\title{
Miniestacas de yuca (Manihot esculenta Crantz): hacia un eficiente sistema de propagación en cultivo de tejidos
}

\author{
Mini-cuttings of cassava (Manihot esculenta \\ Crantz): towards an efficient propagation \\ system in tissue culture
}

\section{Miniestacas mandioca (Manihot esculenta Crantz): Rumo a um sistema eficiente de propagação de cultura de tecidos}

\author{
Miguel Macgayver Bonilla Morales ${ }^{1}$, Sergio Adolfo Sánchez Ordoñez \&
}

Jorge Pachón García ${ }^{3}$

\begin{abstract}
${ }^{1}$ Licenciado en Producción Agropecuaria, Magister en Ciencias Biológicas con énfasis en Recursos Fitogenéticos Neotropicales. ${ }^{2}$ Licenciado en Producción Agropecuaria. ${ }^{3}$ Biólogo, Especialista en Recursos Fitogenéticos. Magister en Ciencias Biológicas, Estudiante de Doctorado en Ciencias Agrarias de la Universidad de los Llanos. Villavicencio. Meta. Colombia

1Departamento de Ciencias Biológicas. Facultad de Ciencias Agropecuarias. Universidad Nacional de Colombia Sede Palmira. Palmira. Colombia. ${ }^{2}$ Unidad Educativa trietnica YAALIAKEISY. Puerto

Gaitán. Meta. Colombia. ${ }^{3}$ Departamento de Ciencias Básicas, Facultad de Ciencias Básicas e Ingenierías. Universidad de los Llanos. Villavicencio. Meta. Colombia

1mmbonillam@unal.edu.co, 25ergio-Ipa@hotmail.com, 3jotapachon@hotmail.com
\end{abstract}

\section{Resumen}

Tradicionalmente, la yuca ha sido una fuente de carbohidratos para sectores de la población con bajos niveles de ingreso a nivel mundial, por lo que está implícita en la seguridad y soberanía alimentaria de la mayoría de los países denominados del tercer mundo. De esta manera, en sistemas de propagación para la regulación de problemas fitosanitarios y producción masiva, las técnicas de cultivo de tejidos, facilitan estos procesos en plantas con propagación vegetativa como la yuca. Sin embargo, el paso más costoso en el sistema, es la introducción y propagación a nivel in vitro, que luego serán endurecidas en la etapa ex vitro y llevadas a campo. Por su parte, la generación de miniestacas permite la obtención de semilla asexual o estacas de plantas endurecidas que están en proceso de finalización de la etapa ex vitro y que en vez de ir a campo se multiplican para que el sistema de producción de plantas sea más eficiente, pues de cada planta se pueden obtener de 4-6 miniestacas, que no tienen necesidad de aclimatación y, por ende, va a ser una producción segura de una nueva planta por miniestacas que se siembre. De esta manera, el sistema de propagación en cultivo de tejidos vegetales en yuca tiende a ser mejor aprovechado y rentable, pues el proceso será tanto a nivel in vitro como ex vitro.

Palabras clave: yuca, miniestacas, propagación ex vitro, seguridad alimentaria.

\section{Abstract}

Traditionally, cassava has been a source of carbohydrates for sectors of the population with low 
income levels worldwide, so it is implicit in the food security and sovereignty of most Third World countries. Thus, tissue culture techniques facilitate the propagation systems for regulating phytosanitary problems and mass production, in plants with vegetative propagation like cassava. However, the most expensive step in the system is the introduction and propagation in vitro level, which will then be hardened ex vitro and then taken to field. Meanwhile, the generation of mini-cuttings allows obtaining asexual seed or cuttings hardened in the finalization process of the ex vitro stage and instead of going into the field are multiplied so the plants production system could be more efficient since approximately 4-6 mini-cuttings are obtained from each plant; those mini-cuttings do not need time for acclimatization, therefore the production of a new plant using minicuttings is going to be safe. Thus, the propagation system in plant tissue culture in cassava tends to be used and has a satisfactory profitable, because the process will be both in vitro and ex vitro level.

Key-words: cassava, mini-cuttings, propagation ex vitro, food security.

\section{Resumo}

Tradicionalmente, a mandioca tem sido uma fonte de hidratos de carbono para os setores da população com baixos níveis de rendimento em todo o mundo, por isso está implícito na segurança e soberania alimentar da maioria dos países chamados de terceiro mundo. Assim, os sistemas de propagação para regular problemas fitossanitários e de produção em massa, técnicas de cultura de tecidos, estão facilitando esses processos em plantas com propagação vegetativa como a mandioca. No entanto, o passo mais caro desse sistema é a introdução e propagação in vitro, que apos vai para o endurecimento ex vitro para ser levado para campo. En quanto isso, a geração de mini-estacas permite a obtenção de plantas assexuadas de sementes ou mudas endurecidas que estão em processo de conclusão da etapa ex vitro e em vez de ir para o campo são multiplicados para o sistema de unidade de produção mais eficiente, de cada planta pode ser obtidas 4-6 mini-estacas, que não tem necessidade de aclimatação e, portanto, será uma produção segura de uma nova planta que é plantada por miniestacas. Assim, o sistema de propagação em cultura de tecidos vegetais na mandioca tende a ser melhor explorada e rentável, porque o processo será tanto ao nível in vitro como ex vitro.

Palavras-chave: mandioca, miniestacas, propagação ex vitro, a segurança alimentar

\section{Introducción}

La yuca ( $M$. esculenta Crantz), es la cuarta fuente de calorías para alrededor de 500 millones de personas, después del arroz, el azúcar y el maíz, en lo referente a cantidad de calorías producidas, se cultiva fundamentalmente en los trópicos y en terrenos considerados marginales, infértiles, ácidos y con largos períodos de sequía (Suárez \& Mederos, 2011). De esta manera, es considerado como uno de los recursos fitogenéticos más importantes para cubrir procesos de seguridad alimentaria en comunidades rurales, campesinas, y como fuente de carbohidratos en las ciudades para sectores de la población con bajos niveles de ingreso a nivel mundial (FAO, 2010).
En yuca, se han desarrollado investigaciones que abarcan desde la siembra hasta el manejo poscosecha, con la finalidad de tener paquetes tecnológicos para el cultivo (Arismendi, 2001). No obstante, la yuca presenta otro usos, como follaje para la producción animal (Preston, Rodríguez, Nguyen \& Le, 1998; Souza et al., 2006), aprovechamiento del almidón para la generación de agentes solifidicantes en cultivo vegetales (Romaym, Matheus, Gerstl, Rueda \& Santana, 2006), o biocombustibles como alternativas limpias en mejora de combustibles fósiles (Cortés, Chavarriaga \& López, 2010). 
La herramienta de cultivo de tejidos mediante la propagación in vitro permite en especies con multiplicación vegetativa la producción masiva de plántulas, libres de patógenos, a bajo costo, en espacio reducido, en menor tiempo, bajo condiciones controladas, con alternativas de establecimiento de bancos de germoplasma, conservación e intercambio de material vegetal (Bonilla \& Hernández, 2012; Bonilla, Mancipe \& Aguirre, 2015). Por lo tanto, la yuca ha resultado ser muy útil para la multiplicación masiva, limpieza de enfermedades y mejoramiento genético (Misikita, Ihemere, Siritunga \& Sayre, 2007; Bonilla, Pachón \& Moreno, 2015).

La producción masiva de plantas se hace a través de procesos in vitro en el laboratorio (Konan, Shöpe, Cárcamo, Beachy \& Fauquet, 1997; Ramírez, Guevara \& Escobar, 2012), y generalmente esta sesgada a este manejo para la generación de material vegetal, que se llevará a la fase ex vitro y luego a campo. Por este motivo, el objetivo de este artículo es definir el protocolo para la propagación y crecimiento de miniestacas de $M$. esculenta variedad brasilera, que permita hacer más eficiente el sistema de proliferación de plántulas por medio de las técnicas de cultivo de tejidos en la etapa ex vitro, con la finalidad de tener una producción simultánea, in vitro y ex vitro.

\section{Material vegetal in vitro}

Siguiendo lo planteado por Bonilla, Pachón \& Moreno (2015) se seleccionaron vitroplantas de yuca ( $M$. esculenta) variedad brasilera de octavo subcultivo y con ocho semanas de desarrollo que crecían en frascos de vidrio que contenían $20 \mathrm{ml}$ de medio de cultivo preparado con sales inorgánicas de Murashige \& Skoog (1962), 0,5 $\mathrm{mg} \mathrm{L}^{-1}$ de tiamina-HCL, 100 $\mathrm{mg} \mathrm{L}^{-1}, 100 \mathrm{mg} \mathrm{L}^{-1}$ de myo-inositol, $30 \mathrm{~g} \mathrm{~L}^{-1}$ de sacarosa, 2,3 $\mathrm{g} \mathrm{L}^{-1}$ de agar (Phytagel) y pH ajustado de 5,8. Las condiciones de laboratorio fueron temperatura de $30^{\circ} \mathrm{C}$, intensidad lumínica de 3000 Lux y un fotoperíodo de 16 horas luz y 8 noche (Figura 1).

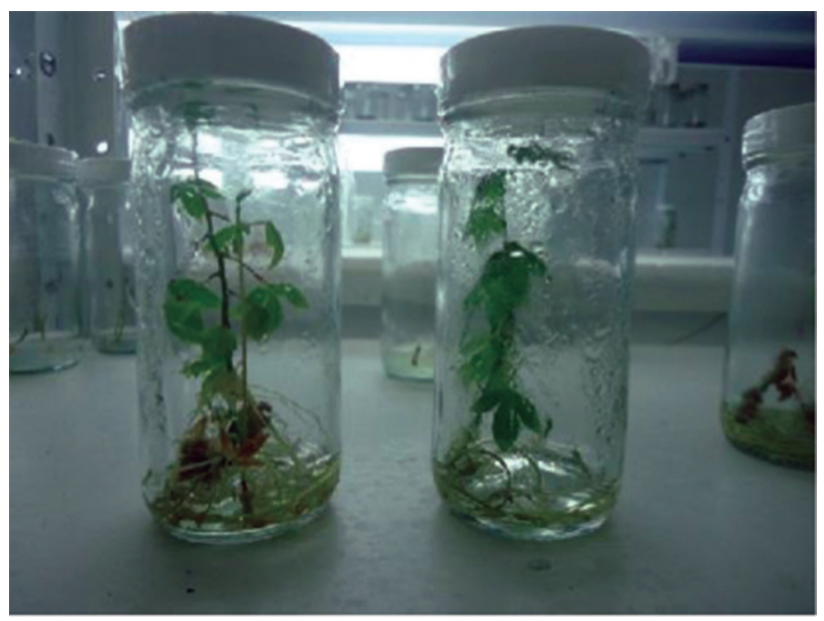

Figura 1. Vitroplantas de yuca (M. esculenta).

\section{Endurecimiento de vitroplantas}

Se siguió el protocolo establecido por Bonilla, Sánchez \& Pachón (2015) donde se dejaron los tarros semi-destapados hasta cuatro días, fuera del cuarto de crecimiento, con una leve radiación solar de 7 am a 9 am y de 3 pm a 5 pm. Luego, se quitó la tapa, vinipel y los residuos del gel junto con las hojas bajeras, para sembrarlas en sustrato MB1 (humus sólido y cascarilla 1:1) esterilizado y su aclimatación se hizo manteniendo en cámara humedad y retirada progresivamente de acuerdo con el desarrollo vegetativo (Figura 2).

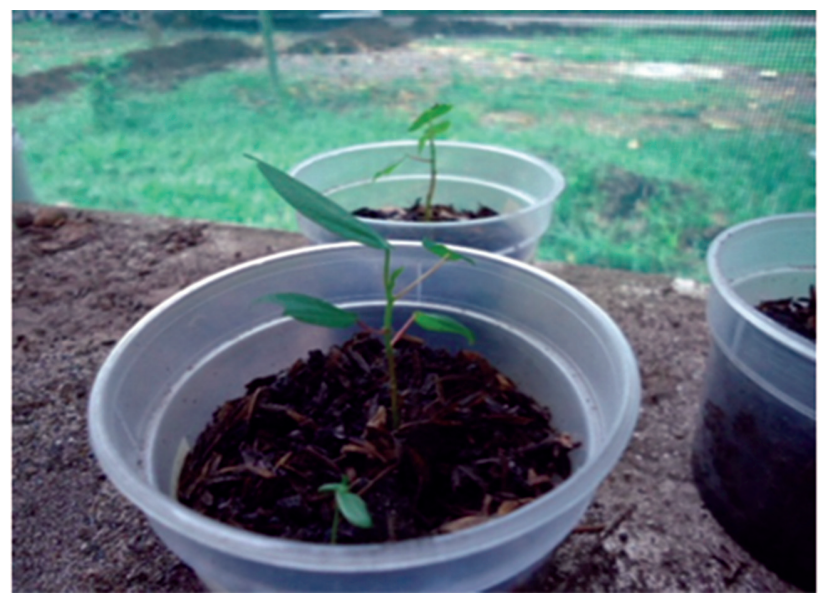

Figura 2. Planta de yuca (M. esculenta) en proceso de endurecimiento. 


\section{Protocolo de propagación de miniestacas}

La selección de las plantas aclimatadas se hace con base en las siguientes características: tallo más herbáceo que leñoso, coloración y porte de la planta idóneo agronómicamente. Adicionalmente, la planta no debe estar infectada o infestada por algún agente patógeno ni atacada por algún insecto. Cabe mencionar que las plantas de 8 a 10 semanas, pueden generar hasta cuatro miniestacas, y con mayor tiempo de aclimatación, se considera una obtención hasta de seis miniestacas (Figura 3).

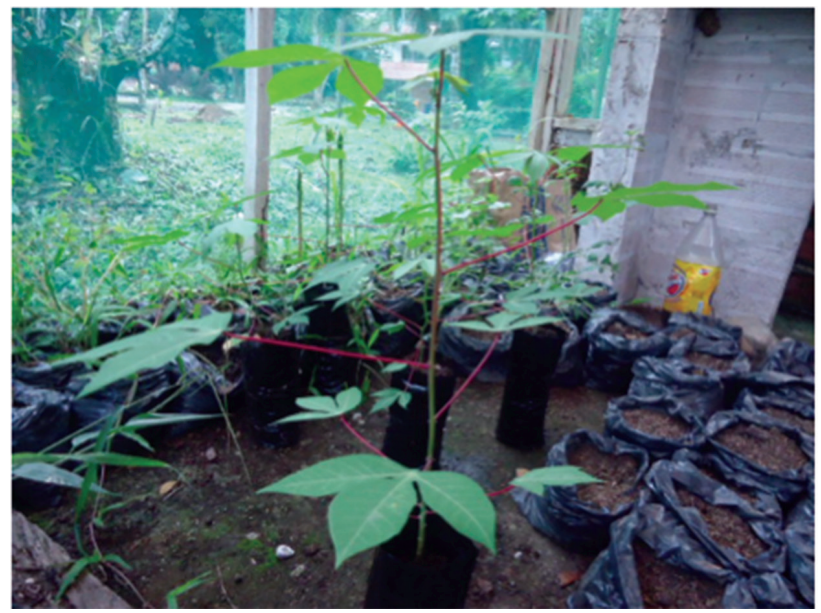

Figura 3. Planta de yuca ( $M$. esculenta) aclimatada.

La cuchilla de bisturí se desinfecta en $\mathrm{NaOCl}$ al $3 \%$ y se hacen los cortes de las hojas desde la base del pecíolo, y luego, para cada una de las miniestacas conservando dos nudos. En seguida se aplica a cada una el protocolo de desinfección por inmersión: Cal (3\%) y fungicida (1\%) por 2 minutos. Las miniestacas se siembran en el sustrato que puede ser el mismo utilizado en la etapa ex vitro (Figura 4).

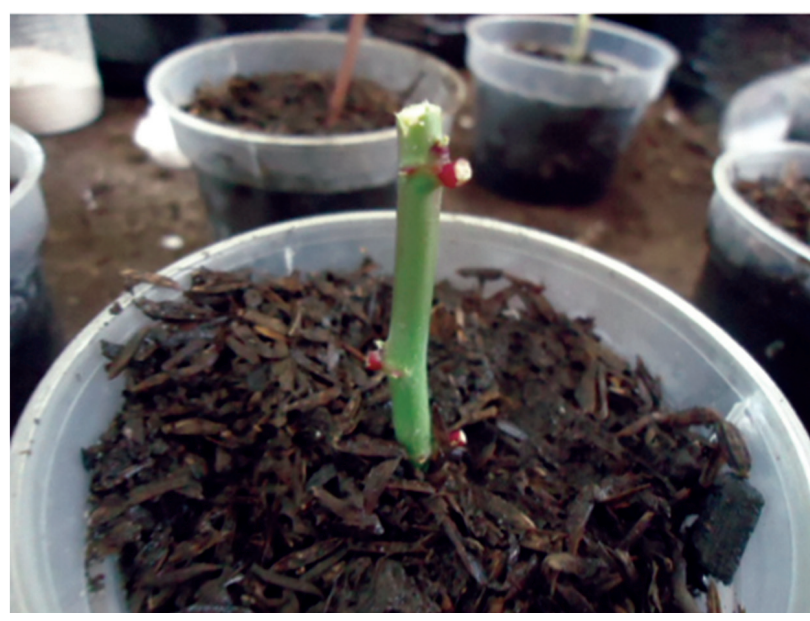

Figura 4. Miniestacas ( $M$. esculenta) sembrada.

Aproximadamente, entre la primera y segunda semanas, aparece el primer brote de hoja (Figura 5), y su crecimiento tarda entre 7-8 semanas para tener material que puede pasar a campo. Siguiendo este orden lógico, la producción de miniestacas va a generar dos zonas de producción, la in vitro en el laboratorio y la ex vitro en invernadero que no solo aclimatizará material, sino que multiplicará aprovechando las plantas existentes.

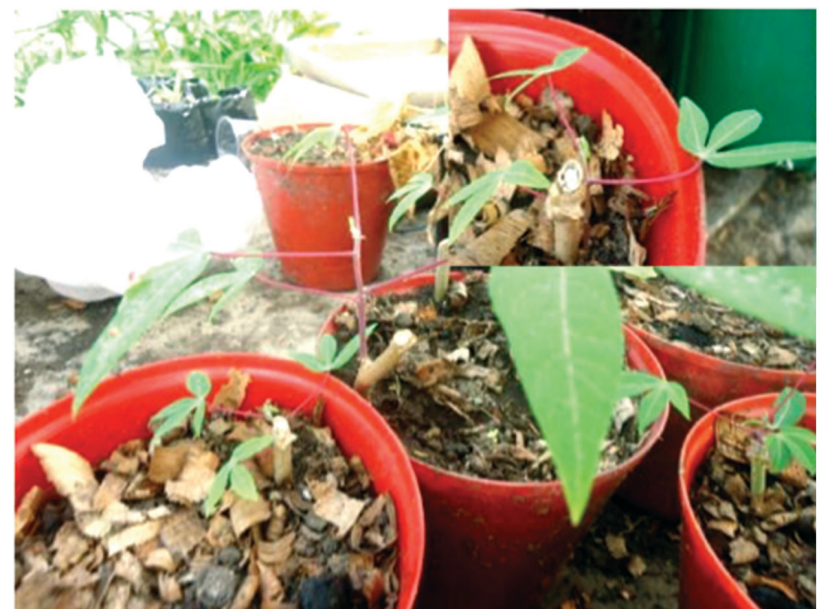

Figura 5. Brote y crecimiento de miniestacas de yuca (M. esculenta). 


\section{Conclusiones}

La multiplicación de material vegetal endurecido por miniestacas es una estrategia que puede permitir aumentar la producción en programas de generación masiva de plantas, y a la vez disminuir los costos y los procesos para su obtención; ya que aprovecha la producción simultánea de material in vitro y la complementa con la ex vitro, de esta manera, el sistema se hace más eficiente y económico.

\section{Agradecimientos}

Los autores expresan sus agradecimientos por el apoyo y financiación por parte de la División de Proyección Social de la Universidad de los Llanos asociada al programa PROGRESO de Acción Social de la República, junto con el Sena sede de Los Naranjos y CORYUMET, para la ejecución del proyecto "Producción de material vegetal de yuca $(M$. esculenta Krantz) libre de patógenos a través de la propagación in vitro". Adicionalmente a los investigadores María Isabel Moreno, Paul Chavarriaga, Óscar Hernández, Viviana Vargas, Tatiana Zabala, Angela Tovar, Hernán Cortés y Carlos Ariel.

\section{Literatura citada}

1. Arismendi, L. (2001). Investigación sobre el cultivo de la yuca (Manihot esculenta Krantz.) en el Oriente de Venezuela. Revista UDO Agrícola. 1(1): 1-10.

2. Bonilla, M, Mancipe, C. \& Aguirre, C. (2015). Conservación in vitro: una perspectiva para el manejo de los Recursos Fitogenéticos. Revista de Investigación Agraria y Ambiental. 6 (1): 67-81.

3. Bonilla, M, Pachón, J. \& M. Moreno. (2015). Propagación in vitro de yuca ( $M$. esculenta Krantz) variedad brasilera: una alternativa de producción de semilla libre de patógenos para el Meta, Colombia. Cuadernos de Recursos Fitogenéticos Neotropicales. 5-6: 48-60.

4. Bonilla, M. \& Hernández, O. (2012). Propagación in vitro de ñame (Dioscorea spp.): una perspectiva en la producción masiva de plántulas y conservación de germoplasma. Agronomía. 20 (2): 65-76.
5. Cortés, S, Chavarriaga, P. \& López, C. (2010). Biocombustibles y biotecnología: la yuca (Manihot esculenta) como modelo de investigación. Acta Biológica Colombiana. 15 (1): 3-24.

6. FAO. (2010). Tratado internacional sobre los recursos fitogenéticos para alimentación y la agricultura. Recuperado de: http://www.fao.org/pgrfa-gpa-archive/ hnd/files/Tratado_internacional_sobre_los_recursos_fitogeneticos_para_la_alimentacion_y_la_agricultura.pdf

7. Konan, N, Shöpe, C, Cárcamo, R, Beachy, R. \& Fauquet, C. (1997). An efficient mass propagation system for cassava (Manihot esculenta Krantz) based on nodal explants and axillary bud-derived meristems. Plant Cell Reports. 16: 444-449.

8. Misikita, W., Ihemere, U., Siritunga, D. \& Sayre, R. (2007). Cassava (Manihot esculenta Crantz). In: Wang, K. Methods in Molecular Biology, vol. 344: Agrobacterium Protocols, 2/e, volume 2. Humana Press Inc., Totowa, NJ. 13-24 pp.

9. Murashige, T. \& Skoog, F. (1962). A revised medium for rapid growth and bioassays with tobacco tissue cultures. Physiology Plant. 15:473- 497.

10. Preston, T., Rodríguez, L., Nguyen, V. \& Le, C. (1998). El forraje de la yuca (Manihot esculenta Krantz) como fuente de proteína para la producción animal en sistemas agroforestales. In: Conferencia Electrónica de la FAO sobre Agroforestería para la Producción Animal en Latinoamérica. Recuperado de: http://www.fao.org/ docrep/014/x1213s/x1213s00.htm

11. Ramírez, H., Guevara, M. \& Escobar, R. (2012). Cultivo de tejidos vegetales, conceptos y prácticas. Universidad Nacional de Colombia, Sede Palmira. Editorial Feriva S.A, Cali, Colombia.

12. Romaym, G., Matheus, J., Gerstl, A., Rueda, R. \& Santana, M. (2006). Almidón modificado de yuca como sustituto económico del agente solidificante para medio de cultivo de tejidos vegetales. Interciencia. 31 (9): 686-689.

13. Souza, E., Guim, A., Batista, A., Zumba, E., Santos, E.,

14. Souza, K., Santos, G., Lins, N. \& Matos, D. (2006). Qualidade de silagens de maniçoba (Manihot epruinosa) emurchecida. Archivos de Zootecnia. 55 (212): 351-360.

15. Suárez, L. \& Mederos, V. (2011). Apuntes sobre el cultivo de la yuca (Manihot esculenta Crantz), Tendencias actuales. Cultivos tropicales. 32 (3): 27-35.

\section{Conflicto de Intereses}

Los autores declaran no tener ningún conflicto de intereses 
UNAP 